\title{
STABILITY AND THERMAL CONDUCTIVITY CHARACTERISTICS OF CARBON NANOTUBE BASED NANOFLUIDS
}

\author{
N.M. Fadhillahanafi, K.Y. Leong ${ }^{*}$ and M.S. Risby \\ Department of Mechanical Engineering, Universiti Pertahanan National Malaysia, \\ Kem Sungai Besi, 57000 Kuala Lumpur, Malaysia \\ Email: leongkinyuen@gmail.com \\ Phone: +603-90513400; Fax: +603-90513472
}

\begin{abstract}
Water, ethylene glycol and engine oil are commonly used in heat exchanger applications. However, these fluids possess low thermal conductivity. The technology advancement in nanotechnology has enabled nano size particles to be included in a base fluid. This new generation of fluids is known as nanofluids. Producing a stable nanofluid with improved thermal conductivity is a challenging process. In the present study, multiwalled carbon nanotubes (MWCNT) based nanofluids with or without surfactant were investigated for their stability and thermal conductivity. The study indicates that nanofluids with added polyvinylpyrrolidone (PVP) surfactant exhibit better stability than nanofluids without surfactant. About $22.2 \%$ thermal conductivity improvement was observed for water containing $0.5 \mathrm{wt} \%$ of MWCNT and $0.01 \mathrm{wt} \%$ of PVP surfactant. The thermal conductivity also increases with increase of the MWCNT's weight fraction. It can be concluded that the addition of PVP and MWCNT into base fluid (water) is vital to produce a stable nanofluid with improved thermal conductivity.
\end{abstract}

Keywords: Carbon nanotube (CNT); stability; thermal conductivity.

\section{INTRODUCTION}

A nanofluid is defined as a suspension of nano-sized particles in a base fluid. This new generation of heat transfer fluids can be used in various heat transfer applications such as in heat exchangers for cooling or heating processes. The inclusion of nanoparticles in the base fluid is capable of enhancing the base fluid's thermal conductivity (Masuda et al., 1993; Pak \& Cho, 1998; Syam Sundar, \& Sharma, 2011a,b; Srinivasa Rao et al., 2011). Typical types of base fluids are water, ethylene glycol and oil, while aluminum oxide and titanium dioxide are often used in nanofluid-related researches. The technology development in nanomaterial science has led to the discovery of carbon nanotubes. Carbon nanotubes possess higher thermal conductivity than other types of metallic or oxides nanoparticles (Nasiri et al., 2012; Azmi, Sharma, Mamat, \& Anuar, 2013). Marquis and Chibante (2005) revealed that the thermal conductivity of carbon nanotubes can reach 1800 to $2000 \mathrm{~W} / \mathrm{mK}$. This provides an alternative option to produce nanofluids with higher thermal conductivity by using carbon nanotubes. However, the stability of carbon nanotube based nanofluids remains a major concern among the thermal researchers. Several researchers have clearly indicated that the production of stable carbon nanotube based nanofluids is a challenging task due to the strong tendency of these nanoparticles to agglomerate, the high aspect ratio and the hydrophobic nature of the nanoparticles themselves (Garg et al., 2009; Lamas et al., 2012; Hussein, Bakar, Kadirgama, \& Sharma, 2013; Hussein, Sharma, Bakar, \& 
Kadirgama, 2013). In addition, Hwang et al. (2007) found that the stability of the nanofluids is strongly affected by the particles morphology, and the chemical structure of the particles and base fluids. Other researchers, Ghadimi et al. (2012), stated that a stable and durable nanofluid is a key factor to achieve optimized thermal property performance. The stability of the carbon nanotube based nanofluids is co-related to their thermal conductivity characteristics (Mahendran, Lee, Sharma, \& Shahrani, 2012). For instance, Talaei et al. (2011) investigated the effect of $\mathrm{COOH}$ concentration on the stability and thermal conductivity of carbon nanotube nanofluids. Their study implied that more highly functionalized groups of nanoparticles produce nanofluids with stable and higher thermal conductivity. Nasiri et al. (2012) investigated different types of carbon nanotube structures, namely single-walled, double-walled, few-walled and multiwalled carbon nanotubes. Their study implied that there is substantial thermal conductivity enhancement for these nanofluids. It was also found that nanofluids with a functionalized carbon nanotube structure are stable with respect to time duration. Among the nanofluids, single-walled carbon nanotubes based nanofluids exhibited the highest thermal conductivity enhancement.

Apart from functionalized carbon nanotubes, researchers have also used surfactant to produce stable carbon nanotubes based nanofluids. Surfactants such as gum arabic, gemini and sodium dodecylbenzene sulfonate (SDBS) are often used in nanofluid research. Gum arabic was used by Ding et al. (2006) in preparing distilled water based multiwalled carbon nanotube nanofluids. The samples produced by the researchers were found to be stable for months without any significant sedimentation. Chen et al. (2008) used gemini cationic surfactant trimethylene-1,3-bis (dodecyldimethyl ammonium bromide) to produce stable water based multiwalled carbon nanotube nanofluids. Phuoc, Massoudi, and Chen (2011) studied the effect of chitosan loading on the multiwalled carbon nanotube in water base fluid. The selected weight fractions for chitosan were $0.1,0.2$ and $0.5 \mathrm{wt} \%$. The authors concluded that chitosan dispersed the carbon nanotubes effectively in the water. Thermal conductivity enhancement was found, ranging from 2.3 to $13 \%$ for nanofluids containing 0.5 to 3 wt $\%$ of multiwalled carbon nanotubes. In another study, Kumaresan and Velraj (2012) used sodium dodecylbenzene sulfonate (SDBS) as a surfactant. About $19.73 \%$ of thermal conductivity enhancement was observed for $0.45 \%$ volume fraction of MWCNT in water/ethylene glycol base fluids at $40^{\circ} \mathrm{C}$. The authors explained that this is attributed to the nature of the heat transfer capacity of the carbon nanotube itself. Furthermore, the authors added that the heat transfer is more effective via carbon nanotubes due to the increased straightness ratio. Harish et al. (2012) studied the thermal conductivity of ethylene glycol containing single-walled carbon nanotubes. Bile salt was used as surfactant in the study. The authors found that a nonlinear enhancement trend is observed when the carbon nanotube loading increases.

In the present study, the focus is on the stability and thermal conductivity aspects of water base fluid containing multiwalled carbon nanotubes. The stability of nanofluids is evaluated through an observation method for a duration of 1 month. Polyvinylpyrrolidone (PVP) was used as a surfactant to produce stable nanofluid samples. The thermal conductivity of nanofluids with and without surfactant was investigated in this study. To the best of the authors' knowledge, there is only limited study which focuses on the application of polyvinylpyrrolidone (PVP) surfactant in nanofluids containing carbon nanotubes. Hopefully, this will fill the gap of research available in this area. Comparison of thermal conductivity data was also made between the experimental and existing Maxwell theoretical model. 


\section{EXPERIMENTAL SETUP}

The multiwalled carbon nanotubes (MWCNT) used in the present study were bought from Chengdu Organic Chemical Co. Ltd., Chinese Academy of Science. The specifications of the MWCNT are shown in Table 1.

Table 1. Specifications of MWCNT

\begin{tabular}{ll}
\hline Technical Characteristic & Specification \\
\hline Outer diameter (OD) & $10-30 \mathrm{~nm}$ \\
Inner diameter (ID) & $5-10 \mathrm{~nm}$ \\
Length & $10-30 \mathrm{um}$ \\
Specific surface area (SSA) & $110 \mathrm{~m}^{2} / \mathrm{g}$ \\
Colour & Black \\
Tap density & $0.14 \mathrm{~g} / \mathrm{cm}^{3}$ \\
Purity & $>90 \%$ \\
True density & $\sim 2.1 \mathrm{~g} / \mathrm{cm}^{3}$ \\
Electric conductivity (EC) & $>100 \mathrm{~s} / \mathrm{cm}^{3}$ \\
Making method & CVD (chemical vapor deposition) \\
\hline
\end{tabular}

Figure 1 shows the FESEM image of dry MWCNT obtained from Nova NanoSEM 240 (FEI). The outer diameter of the MWCNT was found to be within the range declared by the vendor.

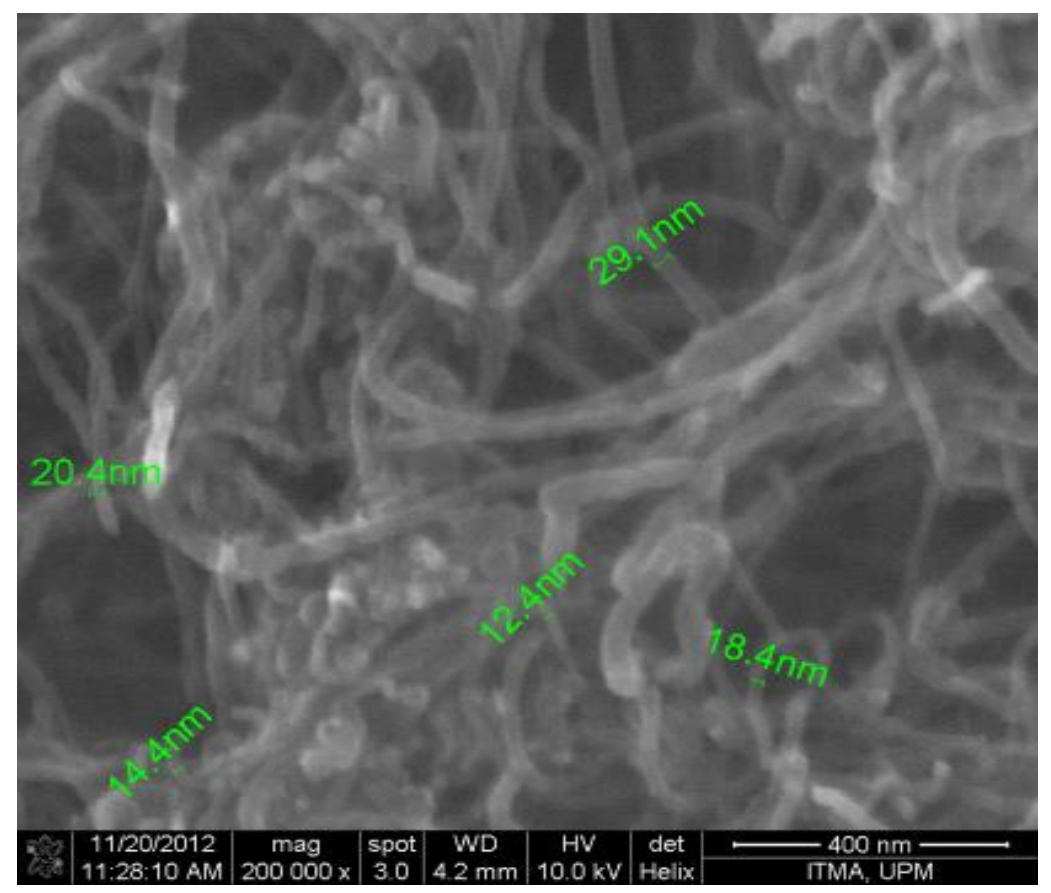

Figure 1. FESEM images of dry MWCNT

Distilled water (DW) and polyvinylpyrrolidone (PVP) were used as base fluid and surfactant, respectively. The nanofluids were prepared using a two-step method. Each of the samples underwent 15 minutes of intensive sonication to disperse the nanoparticles. This process was conducted by using the Qsonica Sonicator (Q700). 
During the sonication process, a half inch (1/2) diameter probe was immersed in the sample. The sample was sonicated for 2 seconds and then paused for 5 seconds. This cycle was repeated for 15 minutes of active sonication time. This duration was chosen in order to minimize the effect of temperature elevation during the sonication process. The composition of the samples is depicted in Table 2.

Table 2. List of test samples

\begin{tabular}{ccc}
\hline Samples & Without surfactant & With surfactant (0.01 wt\% PVP) \\
\hline 1 & $0.01 \mathrm{wt} \%$ MWCNT + DW & $0.01 \mathrm{wt} \%$ MWCNT + DW + PVP \\
2 & $0.05 \mathrm{wt} \%$ MWCNT + DW & $0.05 \mathrm{wt} \%$ MWCNT + DW + PVP \\
3 & $0.1 \mathrm{wt} \%$ MWCNT + DW & $0.1 \mathrm{wt} \% \mathrm{MWCNT}+\mathrm{DW}+\mathrm{PVP}$ \\
4 & $0.3 \mathrm{wt} \% \mathrm{MWCNT}+\mathrm{DW}$ & $0.3 \mathrm{wt} \% \mathrm{MWCNT}+\mathrm{DW}+\mathrm{PVP}$ \\
5 & $0.5 \mathrm{wt} \% \mathrm{MWCNT}+\mathrm{DW}$ & $0.5 \mathrm{wt} \% \mathrm{MWCNT}+\mathrm{DW}+\mathrm{PVP}$ \\
\hline
\end{tabular}

The weight percentage of MWCNT is calculated based on Eq. (1).

Weight percentage of MWCNT $=\frac{\text { Weight of MWCNT }}{\text { Weight of base fluid }} \times 100 \%$

A lower weight percentage of PVP $(0.01 \mathrm{wt} \%)$ was selected in the present study. A higher percentage is not desirable since the thermal conductivity of water decreases with the addition of PVP surfactant (Zhou et al., 2012). As for the investigation of the stability characteristics, the sedimentation of the nanofluid samples was observed for the duration of one month. A KD2-Pro thermal analyzer (Decagon, USA) was used to measure the samples' thermal conductivity at room temperature $\left(25^{\circ} \mathrm{C}\right)$. In order to stabilize the sample's temperature, an experimental setup shown in Figure 2 was used. This is to minimize the effect of temperature variation on the sample's thermal conductivity. Apart from that, 10 readings were recorded for each sample and the average result was taken. This is to minimize the possible errors that might exist during the data collection. The KD2-Pro thermal analyzer was set on automatic mode and left on the bench to avoid any movement or bench vibration during the measurement process. Any movement of the sample would create convection.

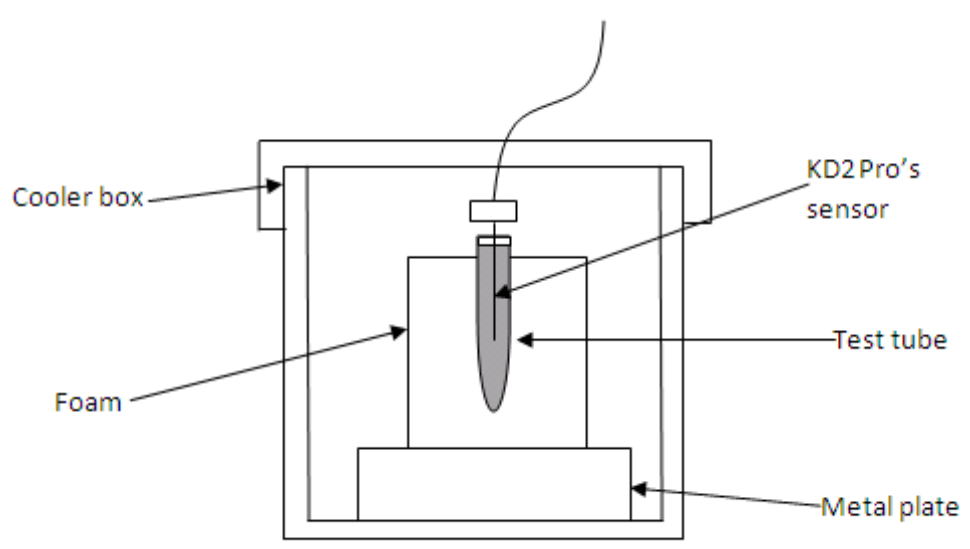

Figure 2. Experimental setup for thermal conductivity measurement 


\section{RESULTS AND DISCUSSION}

The stability characteristics of the carbon nanotube based nanofluids without surfactant are shown in Figures 3(a-f).

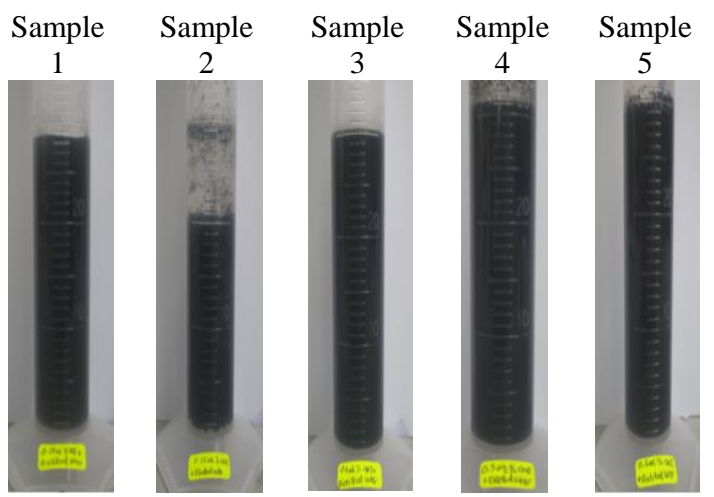

(a) $1^{\text {st }}$ observation (right after sonication)

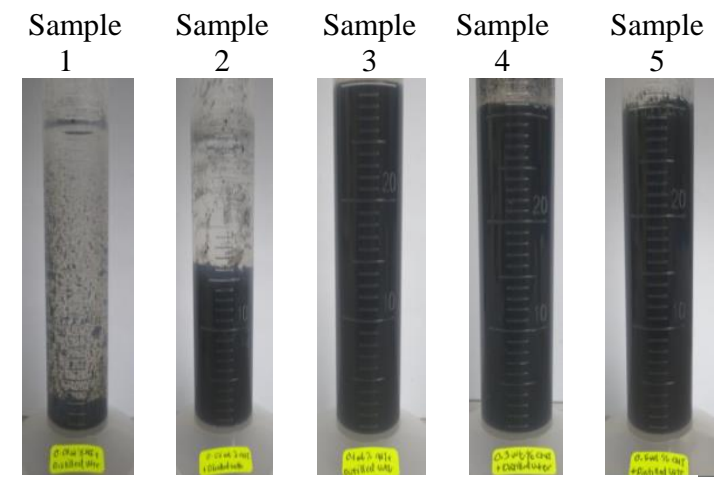

(c) $3^{\text {rd }}$ observation (after 1 week)

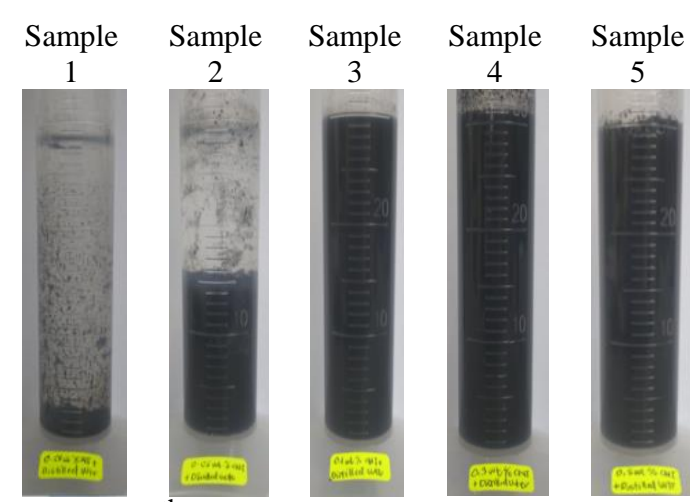

(e) $5^{\text {th }}$ observation (after 3 weeks)

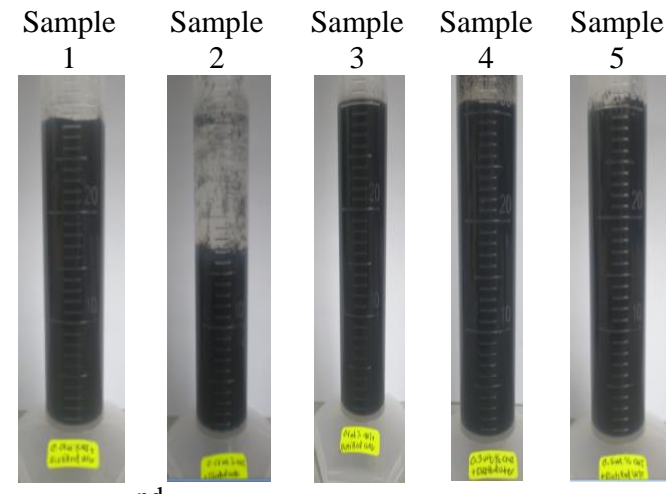

(b) $2^{\text {nd }}$ observation (after 24 hours)

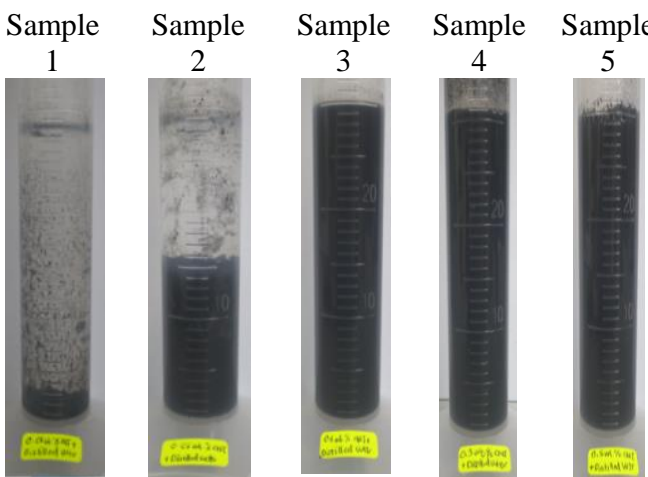

(d) $4^{\text {th }}$ observation (after 2 weeks)
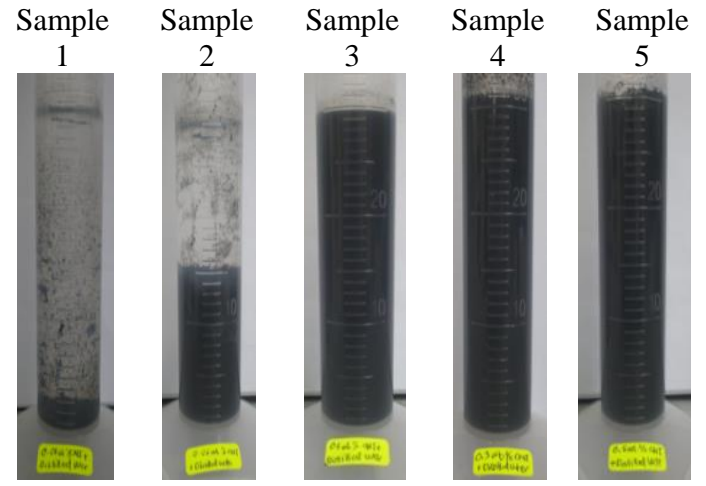

(f) $6^{\text {th }}$ observation (after 1 month)

Figure 3. Stability observations for carbon nanotube nanofluids without surfactant.

Observation from Figures 3(a-f) found that the sonication process alone is not enough to produce a stable nanofluid sample. For instance, sedimentation of nanoparticles was observed for water base fluid containing 0.01 and 0.05 wt $\%$ of MWCNT with respect to time. The sample with $0.05 \mathrm{wt} \%$ of MWCNT exhibited the worst stability in terms of particle sedimentation. The sample showed sedimentation of 
particles even right after the sonication process. This might be due to the hydrophobic nature of the carbon nanotubes. The particles tend to attract each other and thus they are heavier and tend to move downward due to the gravitational force. The study implied that the inclusion of polyvinylpyrrolidone (PVP) surfactant stabilizes the carbon nanotube based nanofluids effectively. This is proven through the stability observation depicted in Figure $4(a-b)$. From these figures, there is no observable particle sedimentation in any of the samples. The addition of surfactant is capable of increasing the repulsive force of the nanoparticles. As a result, the agglomeration of carbon nanotubes can be minimized and subsequently reduce the tendency of the nanoparticles to move downward (sedimentation).

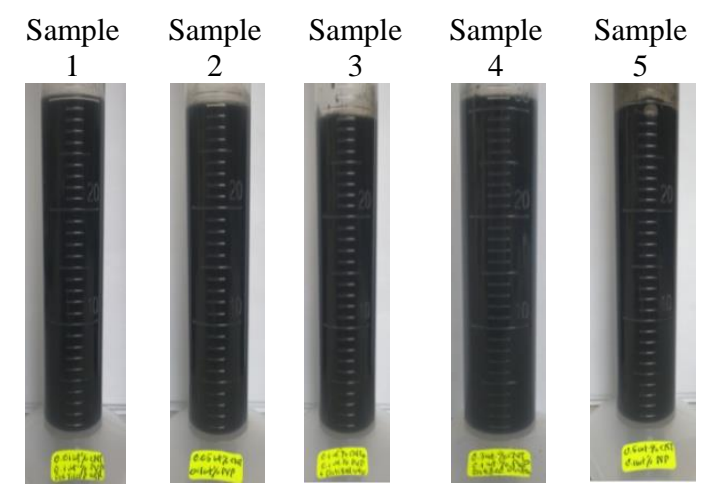

(a) $1^{\text {st }}$ observation (right after sonication)

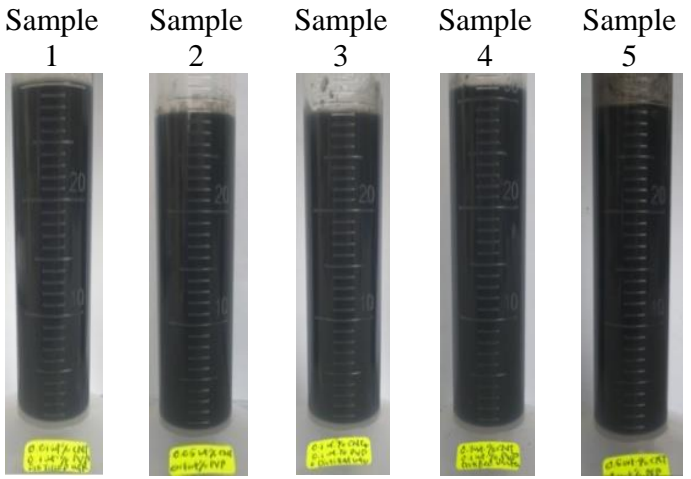

(b) $2^{\text {nd }}$ observation (after 1 month)

Figure 4. Stability observation for carbon nanotube nanofluids with PVP surfactant

The accuracy of the KD2-Pro thermal analyzer was tested by comparing the reference values of water (Incropera et al., 2007) with the experimental result. There is a good agreement between the experiment and reference values, with only $6.1 \%$ deviation recorded. This verifies the accuracy of the KD2-Pro thermal analyzer. Figure 5 depicts the thermal conductivity of water-based carbon nanotube nanofluids with and without surfactant and calculated values from the Maxwell model at $25^{\circ} \mathrm{C}$.

This study indicated that there is only a $2 \%$ thermal conductivity enhancement observed for water containing $0.5 \mathrm{wt} \%$ of MWCNT compared to that of base fluid. The improvement is much lower than distilled water with added PVP surfactant only. However, a substantial thermal conductivity enhancement can be seen when the PVP surfactant is added to the water containing $0.5 \mathrm{wt} \%$ MWCNT. This proved that the combination of surfactant and MWCNT is required to produce nanofluids with superior thermal conductivity. About $22.2 \%$ thermal conductivity increment is achieved for this water-based $0.5 \mathrm{wt} \%$ of MWCNT nanofluids with PVP surfactant compared to that of the base fluid. As mentioned previously, surfactant is capable of dispersing the carbon nanotubes effectively, and consequently it increases the thermal conductivity property. In this investigation, the thermal conductivity of water-based $0.05 \mathrm{wt} \%$ MWCNT nanofluids (without surfactant) was not measured because this sample exhibited particle sedimentation right after the sonication process.

Figure 5 also shows the calculated values based on the Maxwell (1881) model. The model is shown in Eq. (2). 


$$
\frac{\lambda_{\text {eff }}}{\lambda_{\mathrm{f}}}=1+\frac{3 \phi\left(\frac{\lambda_{\mathrm{p}}}{\lambda_{\mathrm{f}}}-1\right)}{\frac{\lambda_{\mathrm{p}}}{\lambda_{\mathrm{f}}}+2-\phi\left(\frac{\lambda_{\mathrm{p}}}{\lambda_{\mathrm{f}}}-1\right)}
$$

where $\lambda_{\text {eff }}$ is the effective thermal conductivity of the nanofluids, $\lambda_{\mathrm{f}}$ is the thermal conductivity of the base fluid, $\lambda_{p}$ is the thermal conductivity of the particle (assuming the thermal conductivity of the carbon nanotubes equals $2000 \mathrm{~W} / \mathrm{mK}$ ) and $\phi$ is the particle volume fraction. This shows that not much thermal conductivity increment is observed from the values calculated from the Maxwell model compared to the experimental data of nanofluids with surfactant. This is because the Maxwell model does not consider factors such as the surfactant and the shape of the carbon nanotube nanoparticles. However, the thermal conductivity of nanofluids without surfactant is well predicted by the Maxwell model. Generally, it can be seen that the thermal conductivity of the base fluid increases with increase of the MWCNT's particle loading.

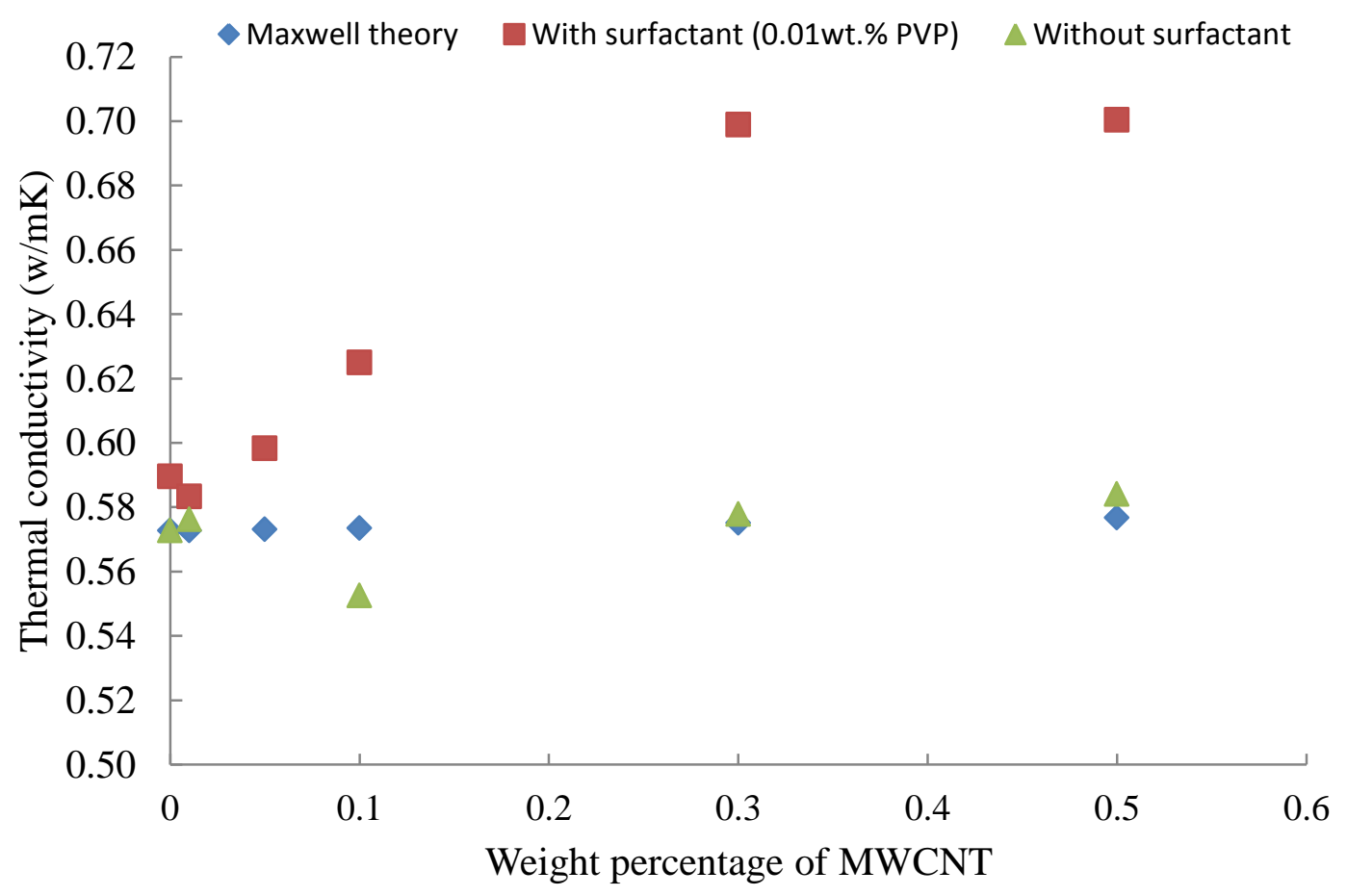

Figure 5. Thermal conductivity of water-based carbon nanotube nanofluids with and without surfactant at $25^{\circ} \mathrm{C}$

\section{CONCLUSIONS}

From the present study, it can be concluded that water-based multiwalled carbon nanotube-based nanofluids with PVP surfactant are more stable than samples without surfactant. No obvious particle sedimentation is observed when the samples have added PVP surfactant. The thermal conductivity enhancement of the water-based carbon nanotube nanofluids with surfactant is higher than without surfactant. About $22.2 \%$ enhancement is observed for water-based fluid containing $0.5 \mathrm{wt} \%$ of MWCNT and $0.01 \mathrm{wt} \%$ of PVP surfactant. However, the thermal conductivity of nanofluids with surfactant is not well predicted by the Maxwell model. For future study, it is 
recommended that the stability of carbon nanotube-based nanofluid is measured through the zeta potential analyzer in order to investigate the particles agglomeration. The effect of other factors such as $\mathrm{pH}$, size of carbon nanotubes, and temperature on thermal conductivity should be investigated.

\section{ACKNOWLEDGMENT}

The authors would like to acknowledge the Ministry of Higher Education of Malaysia and Universiti Pertahanan Nasional Malaysia, Kuala Lumpur, Malaysia for their financial support under FRGS/1/2012/TK01/UPNM/03/2.

\section{REFERENCES}

Azmi, W. H., Sharma, K. V., Mamat, R., \& Anuar, S. (2013). Nanofluid properties for forced convection heat transfer: an overview. Journal of Mechanical Engineering and Sciences, 4, 397-408.

Chen, L., Xie, H., Li, Y., \& Yu, W. (2008). Applications of cationic gemini surfactant in preparing multi-walled carbon nanotube contained nanofluids. Colloids and Surfaces A: Physicochemical and Engineering Aspects, 330, 176-179.

Choi, S. U. S. (1995). Enhancing thermal conductivity of fluid with nanoparticles. In D. A. Siginer \& H. P. Wang (eds.), Developments and applications of nonNewtonian flows, FED-V.231/ MD-V.66. ASME, pp. 99-105.

Ding, Y., Alias, H., Wen, D., \& Williams, R. A. (2006). Heat transfer of aqueous suspensions of carbon nanotubes (CNT nanofluids). International Journal of Heat and Mass Transfer, 49, 240-250.

Garg, P., Alvarado, J. L., Marsh, C., Carlson, T. A., Kessler, D. A., \& Annamalai, K. (2009). An experimental study on the effect of ultrasonication on viscosity and heat transfer performance of multi-wall carbon nanotube-based aqueous nanofluids. International Journal of Heat and Mass Transfer, 52, 5090-5101.

Ghadimi, A., Saidur, R., \& Metselaar, H. S. C. (2011). A review of nanofluid stability properties and characterization in stationary conditions. International Journal of Heat and Mass Transfer, 54, 4051-4068.

Harish, S., Ishikawa, K., Einarsson, E., Aikawa, S., Chiashi, S., Shiomi, J., \& Maruyama, S. (2012). Enhanced thermal conductivity of ethylene glycol with single-walled carbon nanotube inclusions. International Journal of Heat and Mass Transfer, 55, 3885-3890.

Hussein, A. M., Sharma, K. V., Bakar, R. A., \& Kadirgama, K. (2013). Heat transfer enhancement with nanofluids-a review. Journal of Mechanical Engineering and Sciences, 4, 452-461.

Hussein, A. M., Bakar, R. A., Kadirgama, K., \& Sharma, K. V. (2013). Experimental measurements of nanofluids thermal properties. International Journal of Automotive and Mechanical Engineering, 7, 850-863.Hwang, Y., Lee, J. K., Lee, C. H., Jung, Y. M., Cheong, S. I., Lee, C. G., Ku, B. C., \& Jang, S. P. (2007). Stability and thermal conductivity characteristics of nanofluids. Thermochimica Acta, 455, 70-74.

Incropera, F. P., Dewitt, D. P., Bergman, T. L., \& Lavine, A. S. (2007). Fundamentals of heat and mass transfer (6th ed.). New York: John Wiley. 
Kumaresan, V. \& Velraj, R. (2012). Experimental investigation of the thermo-physical properties of water-ethylene glycol mixture based CNT nanofluids. Thermochimica Acta, 545, 180-186.

Lamas, B., Abreu, B., Fonseca, A., Martins, N., \& Oliveira, M. (2012). Assessing colloidal stability of long term MWCNT based nanofluids. Journal of Colloid and Interface Science, 381, 17-23.

Mahendran, M., Lee, G. C., Sharma, K. V., \& Shahrani, A. (2012). Performance of evacuated tube solar collector using water-based titanium oxide $\left(\mathrm{TiO}_{2}\right)$ nanofluid. Journal of Mechanical Engineering and Sciences, 3, 301-310.

Marquis, F. D. S., Chibante, L. P. F. (2005). Improving the heat transfer of nanofluids and nanolubricants with carbon nanotubes. Journal of the Minerals, Metals and Materials Society, 57, 32-43.

Masuda, H., Ebata, A., Teramae, K., \& Hishinuma, N. (1993). Alteration of thermal conductivity and viscosity of liquid by dispersing ultra-fine particles (dispersion of $\gamma$ $\mathrm{Al}_{2} \mathrm{O}_{3}, \mathrm{SiO}_{2}$ and $\mathrm{TiO}_{2}$ ultra-fine particles). Netsu Bussei (in Japanese), 4(4), 227 233.

Maxwell, J. C. (1881). A treatise on electricity and magnetism, ( $2^{\text {nd }}$ ed.), vol. 1 , Clarendon Press: Oxford, UK.

Nasiri, A., Shariaty-Niasar, M., Rashidi, A. M., \& Khodafarin, R. (2012). Effect of CNT structures on thermal conductivity and stability of nanofluid. International Journal of Heat and Mass Transfer, 55, 1529-1535.

Pak, B. C. \& Cho, Y. I. (1998). Hydrodynamic and heat transfer study of dispersed fluids with submicron metallic oxide particles. Experimental Heat Transfer, 11, 151-170.

Phuoc, T. X., Massoudi, M., \& Chen, R.-H. (2011). Viscosity and thermal conductivity of nanofluids containing multi-walled carbon nanotubes stabilized by chitosan. International Journal of Thermal Sciences, 50, 12-18.

Srinivasa Rao, G., Sharma, K. V., Chary, S. P., Bakar, R. A., Rahman, M. M., Kadirgama, K., \& Noor, M. M. (2011). Experimental study on heat transfer coefficient and friction factor of $\mathrm{Al}_{2} \mathrm{O}_{3}$ nanofluid in a packed bed column. Journal of Mechanical Engineering and Sciences, 1, 1-15.

Syam Sundar, L., \& Sharma, K. V. (2011a). An experimental study heat transfer and friction factor of $\mathrm{Al}_{2} \mathrm{O}_{3}$ nanofluid. Journal of Mechanical Engineering and Sciences, 1, 99-112.

Syam Sundar, L., \& Sharma, K. V. (2011b). Laminar convective heat transfer and friction factor of $\mathrm{Al}_{2} \mathrm{O}_{3}$ nanofluid in circular tube fitted with twisted tape inserts. International Journal of Automotive and Mechanical Engineering, 3, 265-278.

Talaei, Z., Mahjoub, A. R., Rashidi, A. M., Amrollahi, A., \& Emami Meibodi, M. (2012). The effect of functionalized group concentration on the stability and thermal conductivity of carbon nanotube fluid as heat transfer media. International Communications in Heat and Mass Transfer, 38, 513-517.

Zhou, M. Z., Xia, G. D., Li, J, Chai, L., \& Zhou, L. J. (2012). Analysis of factors influencing thermal conductivity and viscosity in different kinds of surfactant solutions. Experimental Thermal and Fluid Science, 36, 22-29. 